Journal of ASTM International, September, 2012, Vol. X No. X

Paper ID: XXXXX

Available online at www.astm.org

Joel M. Stoltzfus ${ }^{1}$, Nathan Jeffers ${ }^{2}$, Timothy D. Gallus ${ }^{3}$

\title{
Burning of CP Titanium (Grade 2) in Oxygen-Enriched
}

\section{Atmospheres}

\begin{abstract}
The flammability in oxygen-enriched atmospheres of commercially pure (CP) titanium rods as a function of diameter and test gas pressure was determined. Test samples of varying diameters were ignited at the bottom and burned upward in $70 \% \mathrm{O}_{2} /$ balance $\mathrm{N}_{2}$ and in $99.5+\% \mathrm{O}_{2}$ at various pressures. The burning rate of each ignited sample was determined by observing the apparent regression rate of the melting interface (RRMI) of the burning samples. The burning rate or RRMI increased with decreasing test sample diameter and with increasing test gas pressure and oxygen concentration.
\end{abstract}

KEYWORDS: Flammability, oxygen, titanium, RRMI

\section{Background}

Even though titanium and its alloys are known to be easily ignited [1] and, once ignited, burn vigorously in oxygen enriched atmospheres [2-4], parts made from these materials are sometimes exposed to that environment. For example, titanium alloy blades are used in turbine engines which, by virtue of their high pressures, could be considered oxygen-enriched.

\footnotetext{
1 Oxygen Group Project Leader, Materials and Components Laboratories Office, NASA Johnson Space Center White Sands Test Facility, Las Cruces, New Mexico.

2 Oxygen Group Engineer, NASA Test and Evaluation Contract, NASA Johnson Space Center White Sands Test Facility, Las Cruces, New Mexico.

3 Oxygen Group Engineer, NASA Test and Evaluation Contract, NASA Johnson Space Center White Sands Test Facility, Las Cruces, New Mexico.
} 
To assist in a failure analysis, the NASA Johnson Space Center White Sands Test Facility (WSTF) Oxygen Group was asked to determine the flammability of commercially pure (CP) titanium as a function of test sample diameter, test gas pressure, and oxygen concentration.

\section{Experimental}

\section{Test Samples}

The test material was CP titanium (Grade 2), UNS R50400, with a composition (weight percent) as follows: C 0.1 max, Fe 0.3 max, H 0.015 max, N 0.03 max, O 0.25 max, and Ti 99.2.

Test samples were configured as 6.0-in. (15.2-cm) long rods having diameters of 1/32 in. (0.8 mm), 1/16 in. (1.6 mm), 1/8 in. (3.2 mm), 3/16 in. (4.8 mm), and 1/4 in. (6.4 mm). With the exception of the 1/32 and 1/16-in. (0.8 and $1.6 \mathrm{~mm}$ ) diameter wires, the samples were prepared for test by machining a 0.030-in. (0.762-mm) wide slot through the bottom end through which the igniter wire could be passed to ensure ignition (see Fig. 1).

\section{Ignition Promoters}

CP Titanium (Grade 2) wire with a 0.010-in. (0.254-mm) or 1/32-in. (0.8-mm) diameter was used as the ignition promoter. This wire was wrapped around the bottom end of the test sample and resistively heated to induce melting and subsequent ignition of the igniter wire. The burning igniter wire heated, melted, and ignited the sample to which it was attached.

For the 1/32-in. (0.8-mm) sample, 16 wraps of 0.010 in. $(0.254 \mathrm{~mm})$ diameter wire were wound around the bottom end of the test sample (Fig. 2). For the 1/16-in. (1.6-mm) and 1/8-in. (3.2-mm) samples, 4 wraps of 1/32 in. (0.8 mm) diameter were used (Fig. 2). For the 3/16-in. (4.8-mm) diameter sample, a total of 8 wraps of 1/32 in. $(0.8 \mathrm{~mm})$ diameter were used: 4 wraps were wound through the slot and 4 wraps were wound on top of the wraps in the slot (Fig. 3). For the 1/4-in. (6.4-mm) diameter sample, a total of 8 wraps of 1/32 in. ( $0.8 \mathrm{~mm})$ diameter were 
used: 5 wraps were wound through the slot and 3 wraps were wound on top of the wraps in the slot (Fig. 3).

\section{Test Apparatus}

The tests were conducted in the WSTF High Pressure Promoted Combustion Test Facility. It comprised a 757-in ${ }^{3}$ (12 liters) test chamber (Fig. 4), a 6000-psi (41-mPa) oxygen supply system, a 3000-psi (21-mPa) mixed gas supply system, pressure recording equipment, and 200 frame per second high speed digital camera. The digital camera was used to record test sample burning by observing the regression rate of the melting interface (RRMI) as it progressed up the test sample after ignition. The video images were recorded through a 2-in. $(5-\mathrm{cm})$ diameter sapphire sight glass located adjacent to the bottom end of the test sample.

The test samples were suspended vertically and ignited at the bottom using multiple wraps of resistively heated Grade 2 titanium wire. If the test sample did not propagate, a posttest inspection of each sample verified that it had been melted by the igniter wire to ensure the test was valid.

\section{Test Procedure}

The samples were washed in soapy, deionized water for 5 min, rinsed ten times with deionized water, and blown dry with filtered nitrogen. The samples were individually heat-sealed in clean polyethylene bags.

Just prior to testing, each sample was removed from its bag and the igniter wire was installed. The sample was then mounted vertically in the chamber, being secured at the top (Fig. 5). The igniter leads were connected to the electrical power supply feed-throughs (Fig. 5), and the chamber was sealed. The chamber was purged three times to 500 psig (3.5 mPa) using the test gas and vented to ambient pressure. After purging, the test chamber was pressurized to 
the test pressure, the data acquisition equipment was turned on, and the igniter was initiated by applying power. The test results were observed and recorded. The test chamber was vented, purged, and opened, allowing the sample’s posttest condition to be observed. The burn rates (RRMI) were calculated using measurements taken from the digital video recordings.

\section{Test Conditions}

Tests were conducted on samples of each test diameter at 25 and 200 psia (0.2 and $1.4 \mathrm{mPa}$ ) in $70 \% \mathrm{O}_{2} /$ balance $\mathrm{N}_{2}$. In addition, tests were conducted using $1 / 8 \mathrm{in}$. (3.2 mm) diameter samples in 99.5+\% $\mathrm{O}_{2}$ at 12.4, 25, 50, 100, and 200 psia $(0.09,0.2,0.4,0.7$, and $1.4 \mathrm{mPa}$ ). At least one test, and in some cases two tests, was conducted at each condition. In all tests, the initial test sample, igniter wire, and test chamber temperatures were ambient.

\section{Results}

\section{Uncertainty Analysis}

The reported RRMI for each test was determined by analysis of the digital video recordings. Data sets of elapsed time after the camera trigger point and pixel location were obtained at the first moment of drop separations. Calculations from drop-to-drop differences of melting interface locations divided by the corresponding difference of elapsed time produced the reported RRMIs. This method contains four sources of measurement error which give rise to RRMI uncertainty.

Uncertainty in the RRMI was introduced by the error associated with jitter in the camera clock; pixel bleed due to brightness of the event; melting interface position determination by operator judgment; and tilt of the melting interface due to precessional motion of the molten burning mass attached to the sample rod [5]. Of these error sources, the last two are by far the dominant sources of error. 
The digital camera used to record video images has a highly accurate clock; and since the images were recorded at 200 frames per second of a slow event, the timing error adds very little to the uncertainty of the RRMI determinations. The bleed of brightness from the molten droplet over the melting interface area of the image could have introduced the dominant source of position determination error. However, by adjusting the brightness and contrast of each video recording before the melting interface location was obtained, that error source was reduced to an insignificant level.

The two remaining sources of error were the major contributors to uncertainty in the five rod diameter cases, and both are related to distance measurements. At the zoom level used for video recordings, an operator could only reliably determine position of any point to within \pm 1.5 pixels. This translated into a worst case error of $\pm 2.7 \%$ for distance and therefore RRMI for all recordings.

The natural random tilt of the melting interface due to the precession of the molten, burning droplet around the bottom end of the test sample was another dominant source of error. Fig. 6 shows how the melting interface tilt varied throughout test \#7402. An operator could estimate the average position of an interface that was tilted on an axis parallel with the camera view. However, in every frame it is uncertain whether or not the melting interface is tilted around an axis perpendicular to the camera view. The maximum tilt of the melting interface appeared constant through all video recordings for all sample sizes at \pm 15 degrees. With the maximum tilt constant, larger rod diameters allowed for a larger total vertical offset uncertainty of the melting interface. 
At the smallest two rod diameters, the uncertainty due to operator melting interface determination dominated. At the larger three sample rod diameters, uncertainty due to melting interface tilt dominated. The estimated total uncertainties are listed in Table 1.

Tests in $70 \% \mathrm{O}_{2}$ /balance $\mathrm{N}_{2}$ at 25 psia

Test samples with diameters ranging from $1 / 32$ to $3 / 16$ in. (0.8 to $4.8 \mathrm{~mm}$ ) supported burning in $70 \% \mathrm{O}_{2} /$ balance $\mathrm{N}_{2}$ at 25 psia $(0.2 \mathrm{mPa}$ ) (Table 2$)$. The RRMI decreased with increasing test sample diameter. The 1/4-in. $(6.4 \mathrm{~mm})$ diameter sample ignited but did not support self-sustained burning in all nine tests conducted. In all other cases, the samples burned completely once ignited.

A plot of the RRMI as a function of test sample cross-sectional area is shown in Figure 7. A least squares curve fit through the non-zero burning rate data yields a power curve which describes the burning rate as follows (Eq. 1):

Where:

$$
\mathrm{RRMI}=0.0025 \times \mathrm{A}^{-0.705}
$$

RRMI = regression rate of the melting interface (burning rate) [in/s]

$$
\mathrm{A}=\text { test sample cross-sectional area }\left[\mathrm{in}^{2}\right]
$$

When the cross-sectional area of the test sample was less than $0.0123 \mathrm{in}^{2}\left(0.0794 \mathrm{~cm}^{2}\right)$, or the diameter of the test sample was less than 1/8 in. (3.2 mm), the burning rate increased dramatically.

Tests in $70 \% \mathrm{O}_{2}$ /balance $\mathrm{N}_{2}$ at 200 psia

All the test samples supported burning and burned completely in $70 \% \mathrm{O}_{2}$ /balance $\mathrm{N}_{2}$ at 200 psia (1.4 mPa) (Table 3). The RRMI decreased with increasing test sample diameter. 
A plot of the RRMI as a function of test sample cross-sectional area is shown in Fig. 8. A least squares curve-fit through the non-zero burning rate data yields a power curve which describes the burning rate as follows (Eq. 2):

Where:

$$
\mathrm{RRMI}=0.0116 \times \mathrm{A}^{-0.705}
$$

RRMI = regression rate of the melting interface (burning rate) [in/s]

$$
\mathrm{A}=\text { test sample cross-sectional area }\left[\mathrm{in}^{2}\right]
$$

Similar to the 25 psia data, when the cross-sectional area of the test sample was less than $0.0123 \mathrm{in}^{2}\left(0.0794 \mathrm{~cm}^{2}\right)$, or the diameter of the test sample was less than $1 / 8 \mathrm{in}$. $(3.2 \mathrm{~mm})$, the burning rate increased dramatically.

The test results of 1/8-in. (3.2 mm) diameter CP titanium (Grade 2) rods in $70 \% \mathrm{O}_{2}$ /balance $\mathrm{N}_{2}$ as a function of test gas pressure are shown in Table 4 . As expected, the burning rate (RRMI) increased with increasing pressure and all the samples burned completely, once ignited.

A plot of the RRMI as a function of test gas pressure is shown in Fig. 9. A least squares curve fit through the burning rate data yields a logarithmic function which describes the burning rate as follows (Eq. 3):

Where:

$$
\mathrm{RRMI}=0.0732 \ln (\mathrm{A})^{-0.1769}
$$

$$
\text { RRMI = regression rate of the melting interface (burning rate) [in/s] }
$$$$
\mathrm{A}=\text { test sample cross-sectional area }\left[\mathrm{in}^{2}\right]
$$ 


\section{Tests in $99.5+\%$ Oxygen}

The test results of 1/8-in. (3.2 mm) diameter CP titanium (Grade 2) rods in $99.5+\% \mathrm{O}_{2}$ as a function of test gas pressure are shown in Table 5. Every sample burned completely once ignited and, as expected, the burning rate (RRMI) increased with increasing pressure.

A plot of the RRMI as a function of test gas pressure is shown in Fig. 10. A least squares curve fit through the burning rate data yields a logarithmic curve which describes the burning rate as follows (Eq. 4):

Where:

$$
\mathrm{RRMI}=1.1135 \ln (\mathrm{A})^{-2.8163}
$$

$$
\begin{aligned}
& \text { RRMI = regression rate of the melting interface (burning rate) [in/s] } \\
& \mathrm{A}=\text { test sample cross-sectional area }\left[\mathrm{in}^{2}\right]
\end{aligned}
$$

\section{Discussion}

It is clear that CP titanium will undergo complete, self-sustained burning if ignited in $70 \% \mathrm{O}_{2}$ /balance $\mathrm{N}_{2}$. In addition, it is evident that the burning rate, as indicated by the RRMI, increases as the cross-sectional area decreases. In test gas pressures of 25 and 200 psia (0.2 and $1.4 \mathrm{mPa}$ ), the burning rate increased dramatically when the cross-sectional area was less than $0.0123 \mathrm{in}^{2}\left(0.0794 \mathrm{~cm}^{2}\right)$, which corresponds to a test sample diameter of 1/8 in. (3.2 mm). Effect of Test Gas Pressure (70\% $\mathrm{O}_{2}$ /balance $\mathrm{N}_{2}$ )

When test gas pressure was increased, the burning rate increased for all diameters of CP titanium tested. The magnitude of the increase ranged from 3.3 times for the 1/8-in. (3.2 mm) diameter samples to 4.8 times for the 3/16-in. $(4.8 \mathrm{~mm})$ diameter samples. A comparison of the burning rates in $70 \% \mathrm{O}_{2}$ /balance $\mathrm{N}_{2}$ is shown in Fig. 11 . 


\section{Effect of Oxygen Concentration}

The effect of oxygen concentration on the burning rate of 1/8-in. (3.2 mm) diameter rods of CP titanium is shown in Fig. 12. At 25 psia $(0.2 \mathrm{mPa})$, the rods tested in $99.5+\%$ oxygen burned approximately 5 times the rate of samples tested in $70 \% \mathrm{O}_{2} /$ balance $\mathrm{N}_{2}$. At 50 psia ( $0.4 \mathrm{mPa})$, the rods tested in $99.5+\%$ oxygen burned approximately 12.5 times the rate of samples tested in $70 \% \mathrm{O}_{2}$ /balance $\mathrm{N}_{2}$. At 100 and 200 psia (0.7 and $1.4 \mathrm{mPa}$ ), the rods tested in 99.5+\% oxygen burned approximately 15 times the rate of samples tested in $70 \% \mathrm{O}_{2} /$ balance $\mathrm{N}_{2}$.

The burning rate in 200 psia $(1.4 \mathrm{mPa})$ of $99.5+\%$ oxygen was 6.6 times greater than the burning rate in 25 psia $(0.2 \mathrm{mPa})$ of $99.5+\%$ oxygen. In contrast, the burning rate in 200 psia (1.4 mPa) of $70 \% \mathrm{O}_{2}$ /balance $\mathrm{N}_{2}$ was only 3.3 times greater than the burning rate in 25 psia (0.2 $\mathrm{mPa}$ ) of $70 \% \mathrm{O}_{2} /$ balance $\mathrm{N}_{2}$. It is probable that this was due to the presence of the $30 \% \mathrm{~N}_{2}$ in the mixed gas test atmosphere. It is surmised that the $\mathrm{N}_{2}$ significantly increased the heat transfer from the burning test sample at elevated pressure, reducing the effect of the greater quantity of oxygen available at that pressure.

Direct comparison to previous flammability studies [6,7] of titanium and titanium alloys in $\mathrm{O}_{2}$-enriched atmospheres is not possible, because in those studies burning rates were not measured. They presented threshold pressures (the minimum pressure required to support selfsustained burning) but did not record RRMI. It was observed in the McIlroy paper [7] that 1/8 in. (3.2 mm) diameter CP titanium (ERTi-2) welding filler rods will support burning at oxygen concentrations lower than $70 \% \mathrm{O}_{2}$ /balance $\mathrm{N}_{2}$. They report that in $60 \% \mathrm{O}_{2} /$ balance $\mathrm{N}_{2}$, CP titanium (ERTi-2) will not support burning at 24.7 psia $(0.17 \mathrm{mPa})$ but will burn at $39.7 \mathrm{psia}$ ( $0.27 \mathrm{mPa}$ ) once ignited. In $50 \% \mathrm{O}_{2}$ /balance $\mathrm{N}_{2}$ it will not burn at 39.7 psia $(0.27 \mathrm{mPa})$ but will at 64.7 psia (0.45 $\mathrm{mPa})$. In $40 \% \mathrm{O}_{2}$ /balance $\mathrm{N}_{2}$, they report no self-sustained burning at 
114.7 psia (0.79 $\mathrm{mPa}$ ) but self-sustained burning at $214.7 \mathrm{psia}(1.48 \mathrm{mPa})$. And finally, they observed no self-sustained burning at up to 214.7 psia (1.48 mPa) in $30 \% \mathrm{O}_{2} /$ balance $\mathrm{N}_{2}$.

\section{Conclusion}

CP titanium (Grade 2) is flammable in $70 \% \mathrm{O}_{2}$ /balance $\mathrm{N}_{2}$ pressures as low as 25 psia (0.2 $\mathrm{mPa})$ up to 3/16 in. (5.8 mm) diameter. At 200 psia (1.4 mPa), test samples with diameters up to $1 / 4$ in. (6.4 mm) supported self-sustained burning. The burning rate increased as crosssectional area decreased.

For all diameters of CP titanium and oxygen concentrations tested, the burning rate increased as the test gas pressure was increased. In $70 \% \mathrm{O}_{2} /$ balance $\mathrm{N}_{2}$, the magnitude of the increase ranged from 3.3 to 4.8 times for the various diameter samples. In $95.5+\% \mathrm{O}_{2}$, the burning rate of test samples with 1/8-in. (3.2 mm) diameters increased over an order of magnitude when the test gas pressure was increased from 12.4 to 200 psia (0.09 to $1.4 \mathrm{mPa}$ ).

\section{References}

[1] Key, C. F., and W. A. Reihl. Compatibility of Materials with Liquid Oxygen, NASA Technical Memorandum (TM) X-985, NASA Marshall Space Flight Center, Alabama, 1964.

[2] Laurendeau, N. M. The Ignition Characteristics of Metals in Oxygen-Enriched Atmospheres, Test Report TR-851, Princeton University, Princeton, NJ, 1968.

[3] McKinley, C. “Experimental Ignition and Combustion of Metals,” Oxygen Compressors and Pumps Symposium, Compressed Gas Association, Chantilly, VA, 1971, p. 27-34.

[4] Pelouch, J. J. “Characteristics of Metals That Influence System Safety,” ASRDI Oxygen Technology Survey, Volume VII. NASA Special Publication SP-3077, Aerospace Safety 
Research and Data Institute, National Aeronautics and Space Administration, Washington, D.C., 1974.

[5] Edwards, A.P. R., G. J. A. Chiffoleau, M. J. Maes, and T. A. Steinberg. “Instantaneous RRMI of Iron Rods in Reduced Gravity.” Symposium on Flammability and Sensitivity of Materials in Oxygen-Enriched Atmospheres: Tenth Volume, ASTM STP 1454, T. A.

Steinberg, B. E. Newton, and H. D. Beeson, Eds. American Society for Testing and Materials, West Conshohocken, PA, 2003, pp. 91-101.

[6] Gunaji, M. V., S. Sircar, and H. D. Beeson. "Ignition and Combustion of Titanium and Titanium Alloys,” Symposium on Flammability and Sensitivity of Materials in OxygenEnriched Atmospheres: 7th Volume, ASTM STP 1267, D. D. Janoff, W. T. Royals, and M. V. Gunaji, Eds. American Society for Testing and Materials, Philadelphia, PA, 1995, pp. 81-85.

[7] Zawierucha, R., K. McIlroy, and J. F. Million. "Promoted Ignition-Combustion Behavior of Light Metals in Oxygen Enriched Atmospheres.” Symposium on Flammability and Sensitivity of Materials in Oxygen-Enriched Atmospheres: 7th Volume, ASTM STP 1267, D. D. Janoff, W. T. Royals, and M. V. Gunaji, Eds. American Society for Testing and Materials, Philadelphia, PA, 1995, pp. 69-80. 
Table $1-$ RRMI uncertainty as a function of sample rod diameter.

\begin{tabular}{ccc}
\hline \multicolumn{2}{c}{ Rod Diameter } & $\begin{array}{c}\text { RRMI Uncertainty } \\
( \pm \%)\end{array}$ \\
\cline { 1 - 2 }$($ in. $)$ & $(\mathrm{mm})$ & 2.7 \\
\hline $1 / 32$ & 0.8 & 2.7 \\
$1 / 16$ & 1.6 & 5.1 \\
$1 / 8$ & 3.2 & 7.6 \\
$3 / 16$ & 4.8 & 10 \\
$1 / 4$ & 6.4 & \\
\hline
\end{tabular}

Table 2-Test results in $70 \% \mathrm{O}_{2}$ /balance $\mathrm{N}_{2}$ at 25 psia $(0.2 \mathrm{mPa})$.

\begin{tabular}{|c|c|c|c|c|c|c|c|}
\hline \multirow[t]{2}{*}{ Test No. } & \multicolumn{3}{|c|}{ Sample diameter } & \multicolumn{2}{|c|}{ Cross-sectional area } & \multicolumn{2}{|c|}{ RRMI } \\
\hline & & in) & $(\mathrm{mm})$ & in $^{2}$ & $\mathrm{~cm}^{2}$ & in/s & $\mathrm{cm} / \mathrm{s}$ \\
\hline 7390 & $1 / 32$ & 0.0313 & 0.7950 & 0.0008 & 0.0052 & $0.38 \pm 0.010$ & $0.97 \pm 0.025$ \\
\hline 7391 & $1 / 32$ & 0.0313 & 0.7950 & 0.0008 & 0.0052 & $0.45 \pm 0.012$ & $1.14 \pm 0.031$ \\
\hline 7392 & $1 / 16$ & 0.0625 & 1.5875 & 0.0031 & 0.0199 & $0.14 \pm 0.004$ & $0.36 \pm 0.010$ \\
\hline 7393 & $1 / 16$ & 0.0625 & 1.5875 & 0.0031 & 0.0199 & $0.13 \pm 0.004$ & $0.33 \pm 0.010$ \\
\hline 7394 & $1 / 8$ & 0.1250 & 3.1750 & 0.0123 & 0.0794 & $0.07 \pm 0.004$ & $0.18 \pm 0.010$ \\
\hline 7395 & $1 / 8$ & 0.1250 & 3.1750 & 0.0123 & 0.0794 & $0.06 \pm 0.003$ & $0.15 \pm 0.008$ \\
\hline 7377 & $3 / 16$ & 0.1875 & 4.7625 & 0.0276 & 0.1781 & $0.03 \pm 0.002$ & $0.08 \pm 0.005$ \\
\hline 7378 & $3 / 16$ & 0.1875 & 4.7625 & 0.0276 & 0.1781 & $0.03 \pm 0.002$ & $0.08 \pm 0.005$ \\
\hline 7359-67 & $1 / 4$ & 0.2500 & 6.3500 & 0.0491 & 0.3168 & $0^{\mathrm{a}}$ & $0^{\mathrm{a}}$ \\
\hline
\end{tabular}

Samples ignited but did not propagate. A total of 9 tests were conducted at this test condition.

Table 3-Test results in $70 \% \mathrm{O}_{2} /$ balance $\mathrm{N}_{2}$ at 200 psia $(1.4 \mathrm{mPa})$.

\begin{tabular}{cllccccc}
\hline Test No. & \multicolumn{2}{c}{ Sample diameter } & \multicolumn{2}{c}{ Cross-sectional area } & \multicolumn{2}{c}{ RRMI } \\
\cline { 2 - 7 } & \multicolumn{2}{c}{ (in) } & $(\mathrm{mm})$ & (in $\left.^{2}\right)$ & $\mathrm{cm}^{2}$ & in/s & $\mathrm{cm} / \mathrm{s}$ \\
\hline 7385 & $1 / 32$ & 0.0313 & 0.7950 & 0.0008 & 0.0052 & $1.81 \pm 0.049$ & $4.60 \pm 0.125$ \\
7383 & $1 / 16$ & 0.0625 & 1.5875 & 0.0031 & 0.0199 & $0.48 \pm 0.013$ & $1.22 \pm 0.033$ \\
7384 & $1 / 16$ & 0.0625 & 1.5875 & 0.0031 & 0.0199 & $0.50 \pm 0.014$ & $1.27 \pm 0.036$ \\
7381 & $1 / 8$ & 0.1250 & 3.1750 & 0.0123 & 0.0794 & $0.22 \pm 0.011$ & $0.56 \pm 0.028$ \\
7382 & $1 / 8$ & 0.1250 & 3.1750 & 0.0123 & 0.0794 & $0.21 \pm-0.011$ & $0.53 \pm 0.028$ \\
7380 & $3 / 16$ & 0.1875 & 4.7625 & 0.0276 & 0.1781 & $0.15 \pm-0.011$ & $0.38 \pm 0.028$ \\
7379 & $1 / 4$ & 0.2500 & 6.3500 & 0.0491 & 0.3168 & $0.10 \pm-0.010$ & $0.25 \pm 0.025$ \\
\hline
\end{tabular}


Table 4-Test results of 1/8-in. (3.2 mm) diameter Ti rods in $70 \% \mathrm{O}_{2} /$ balance $\mathrm{N}_{2}$.

\begin{tabular}{ccccc}
\hline Test No. & \multicolumn{2}{c}{ Test Pressure } & \multicolumn{3}{c}{ RRMI } \\
\cline { 2 - 5 } & $(\mathrm{psia})$ & $(\mathrm{mPa})$ & $(\mathrm{in} / \mathrm{s})$ & $(\mathrm{cm} / \mathrm{s})$ \\
\hline 7394 & 25.0 & 0.2 & $0.065 \pm 0.003$ & $0.165 \pm 0.008$ \\
7401 & 50.0 & 0.4 & $0.10 \pm 0.005$ & $0.254 \pm 0.013$ \\
7402 & 100.0 & 0.7 & $0.16 \pm 0.008$ & $0.406 \pm 0.020$ \\
7381 & 200.0 & 1.4 & $0.215 \pm 0.011$ & $0.546 \pm 0.028$ \\
7382 & 200.0 & 1.4 & $0.21 \pm 0.011$ & $0.533 \pm 0.028$ \\
\hline
\end{tabular}

Table 5-Test results of 1/8-in. diameter Ti rods in $100 \% \mathrm{O}_{2}$ as a function of test pressure.

\begin{tabular}{cccccccc}
\hline Test No. & \multicolumn{3}{c}{ Sample diameter } & \multicolumn{2}{c}{ Test Gas Pressure } & \multicolumn{2}{c}{ RRMI } \\
\cline { 2 - 7 } & \multicolumn{2}{c}{ (in) } & $(\mathrm{mm})$ & $(\mathrm{psia})$ & $(\mathrm{mPa})$ & $(\mathrm{in} / \mathrm{s})$ & $(\mathrm{cm} / \mathrm{s})$ \\
\hline 7396 & $1 / 8$ & 0.1250 & 3.2 & 12.4 & 0.09 & $0.31 \pm 0.016$ & $0.787 \pm 0.041$ \\
7397 & $1 / 8$ & 0.1250 & 3.2 & 25 & 0.2 & $0.49 \pm 0.025$ & $1.245 \pm 0.064$ \\
7398 & $1 / 8$ & 0.1250 & 3.2 & 50 & 0.4 & $1.26 \pm 0.064$ & $3.20 \pm 0.163$ \\
7399 & $1 / 8$ & 0.1250 & 3.2 & 100 & 0.7 & $2.41 \pm 0.123$ & $6.121 \pm 0.312$ \\
7400 & $1 / 8$ & 0.1250 & 3.2 & 200 & 1.4 & $3.22 \pm 0.164$ & $8.179 \pm 0.417$ \\
\hline
\end{tabular}




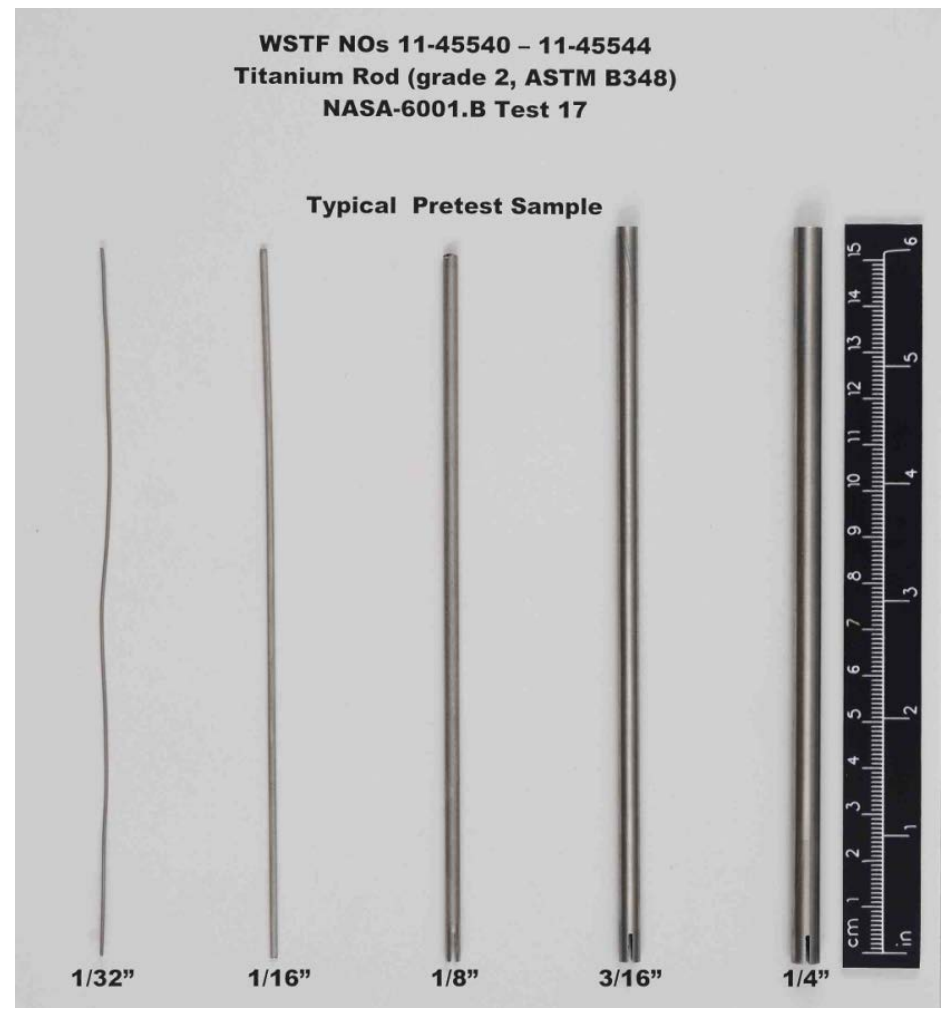

FIG. 1-Photo of CP titanium samples prior to test.

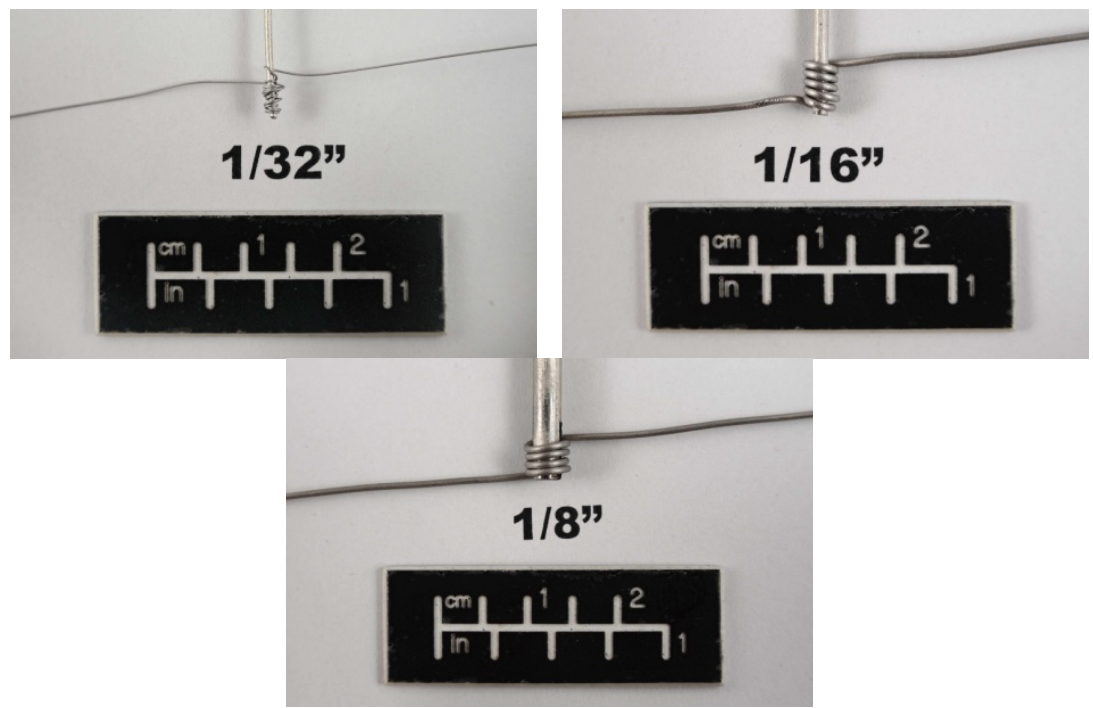

FIG. $2-1 / 32,1 / 16$, and $1 / 8$ in. $(0.8,1.6$, and $3.2 \mathrm{~mm})$ diameter samples with ignition promoters installed. 

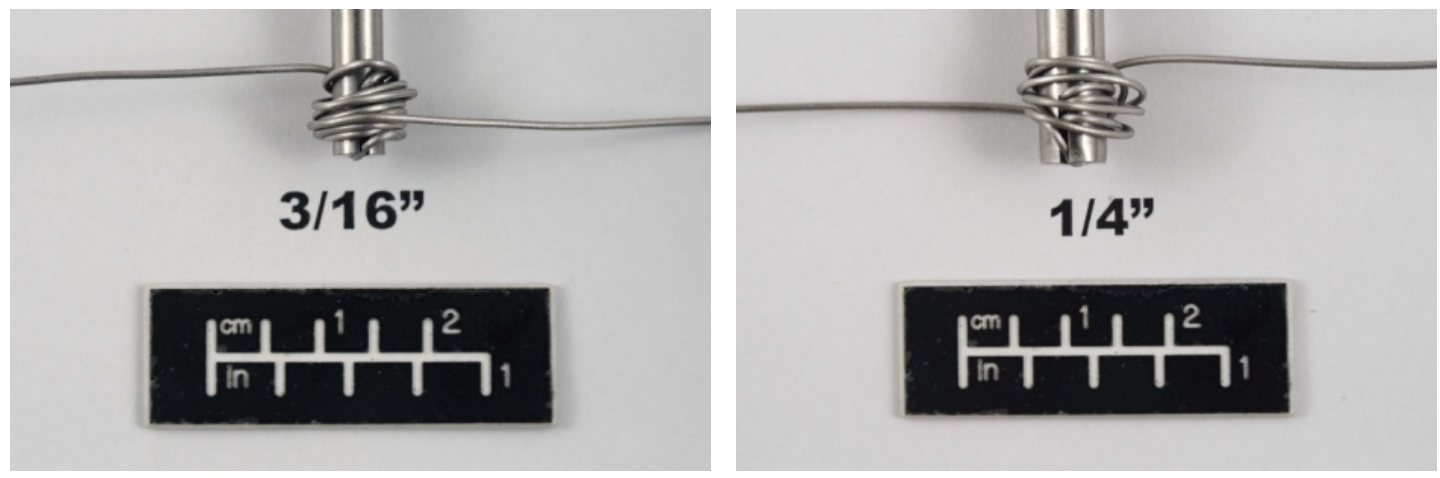

FIG. 3-3/16 and 1/4 in. (4.8 and $6.4 \mathrm{~mm}$ ) diameter samples with ignition promoters installed.

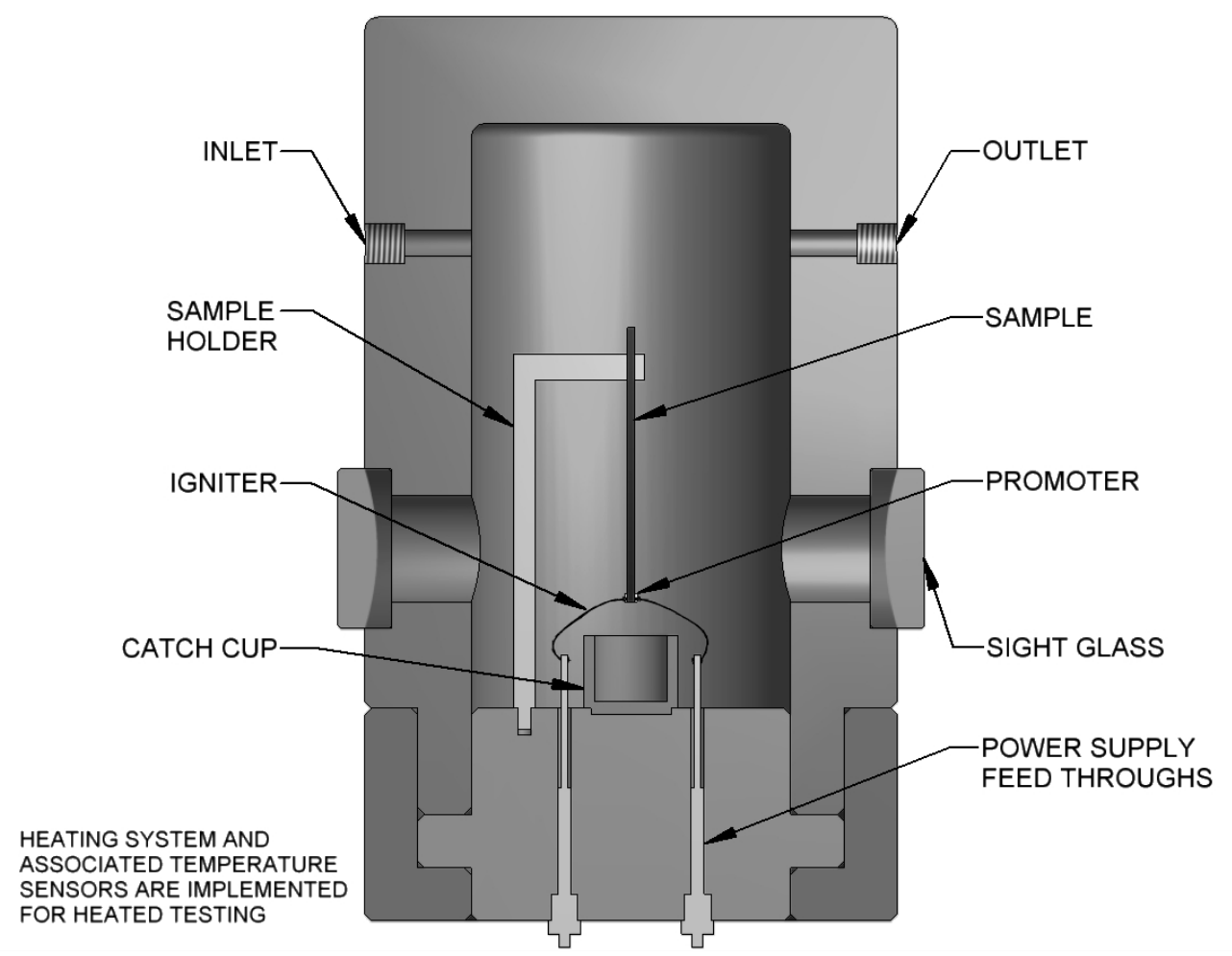

FIG. 4-Schematic of WSTF 757 in $^{3}$ (12 Liters) promoted combustion test chamber. 

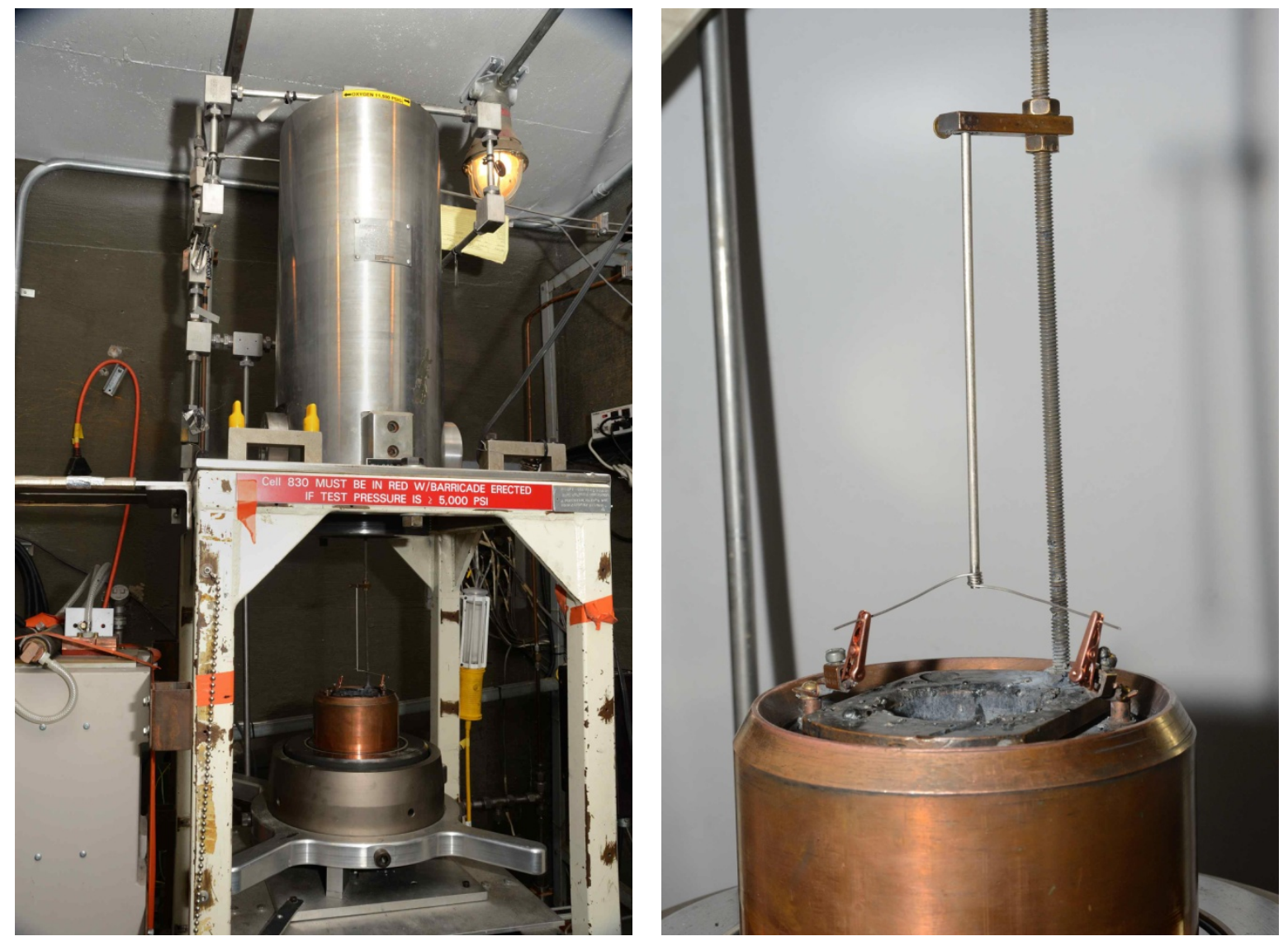

FIG. 5-Test sample installed in test chamber.
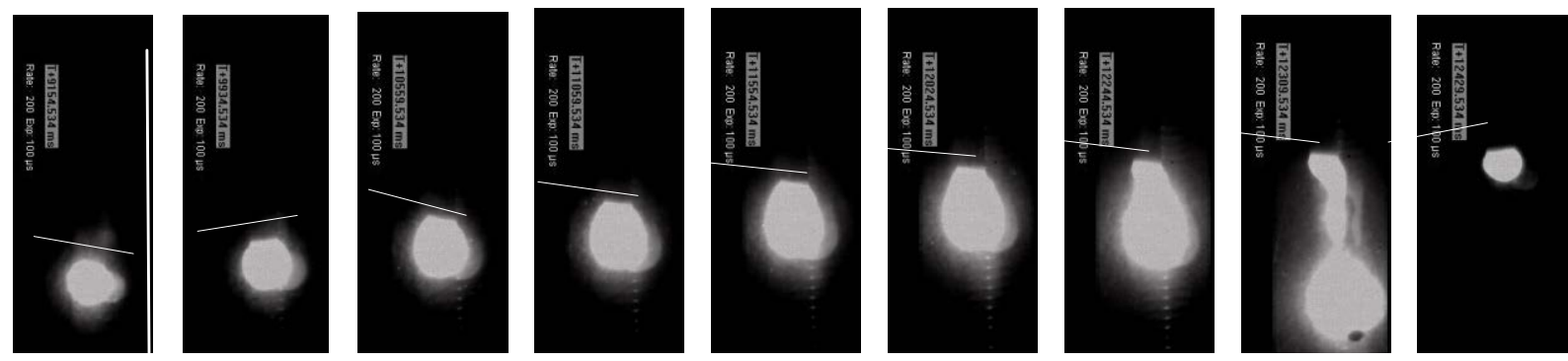

FIG. 6-Burning droplet cycle for Test Number 7402 with melting interface tilt indicated. 


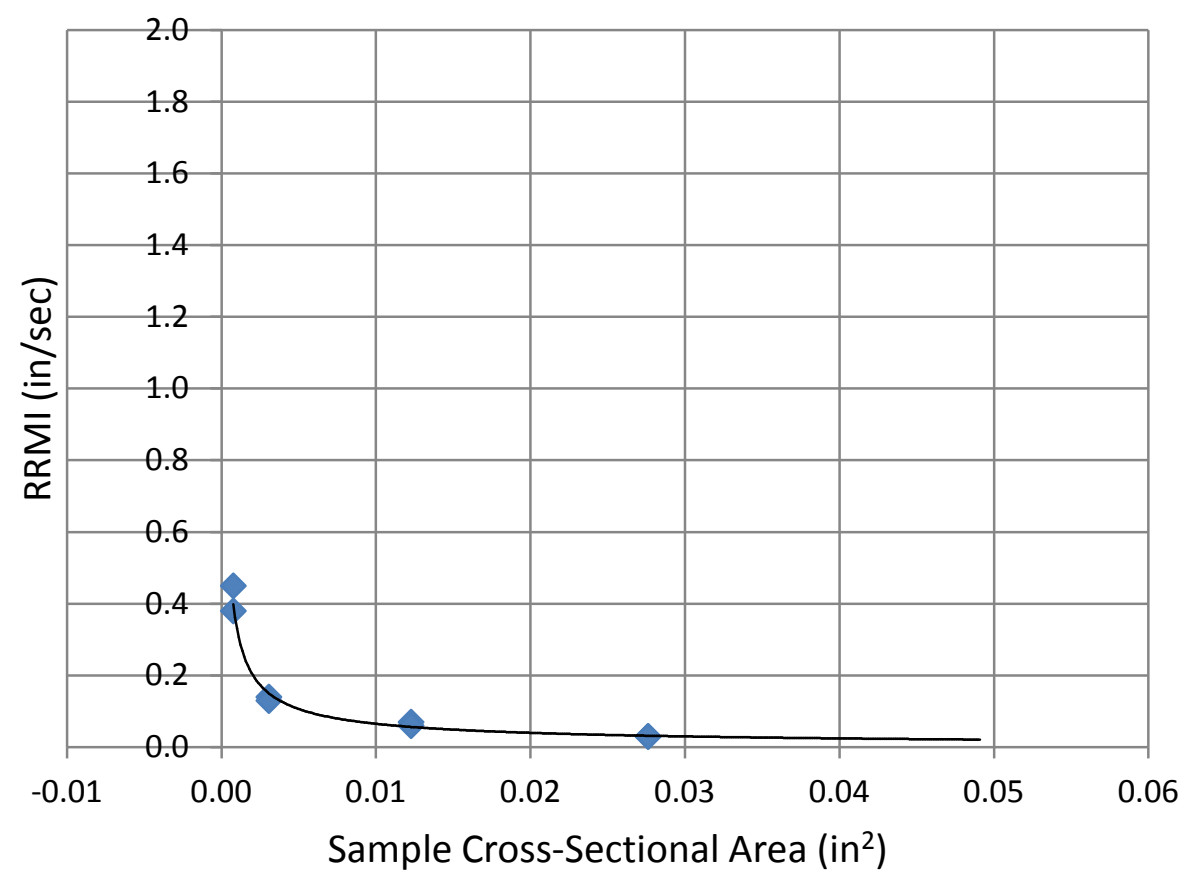

FIG. 7-Plot of burning rate (RRMI) in $70 \% \mathrm{O}_{2} /$ balance $\mathrm{N}_{2}$ at $25 \mathrm{psia}(0.2 \mathrm{mPa})$ as a function of test sample cross-sectional area. (The uncertainty in each data point is smaller than the height of the symbol and is therefore not indicated on the plot.)

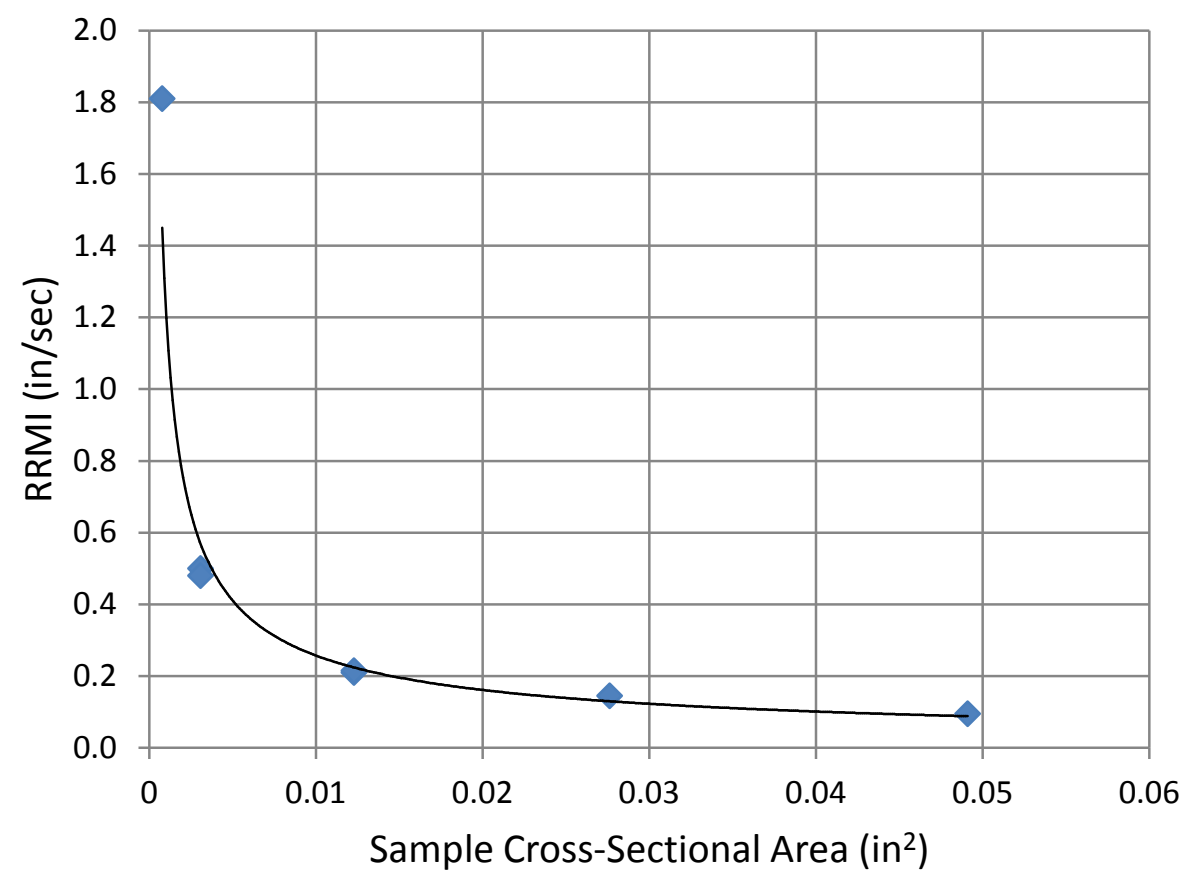

FIG. 8-Plot of burning rate (RRMI) in $70 \% \mathrm{O}_{2} /$ balance $\mathrm{N}_{2}$ at 200 psia $(1.4 \mathrm{mPa}$ ) as a function of test sample cross-sectional area. (The uncertainty in each data point is smaller than the height of the symbol and is therefore not indicated on the plot.) 


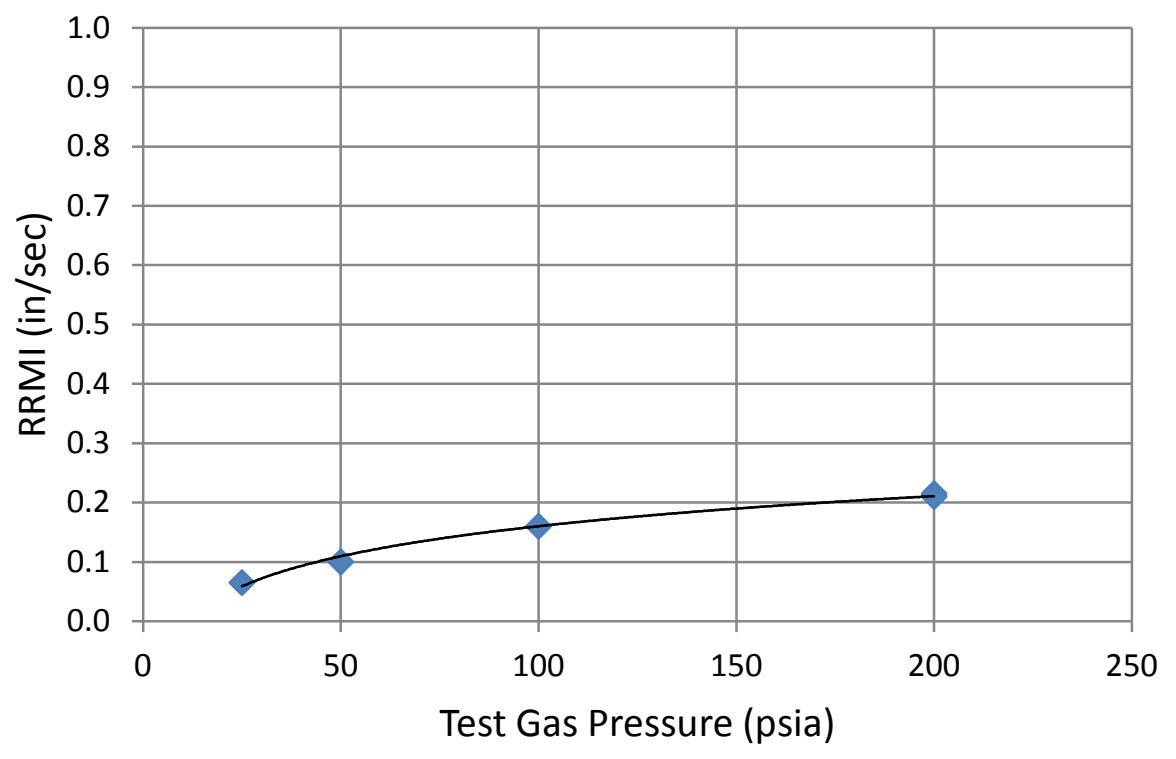

FIG. 9-Plot of burning rate (RRMI) of 1/8 in. (3.2 mm) diameter CP Ti rods in $70 \% \mathrm{O}_{2}$ /balance $\mathrm{N}_{2}$ as a function of test gas pressure. (The uncertainty in each data point is smaller than the height of the symbol and is therefore not indicated on the plot.)

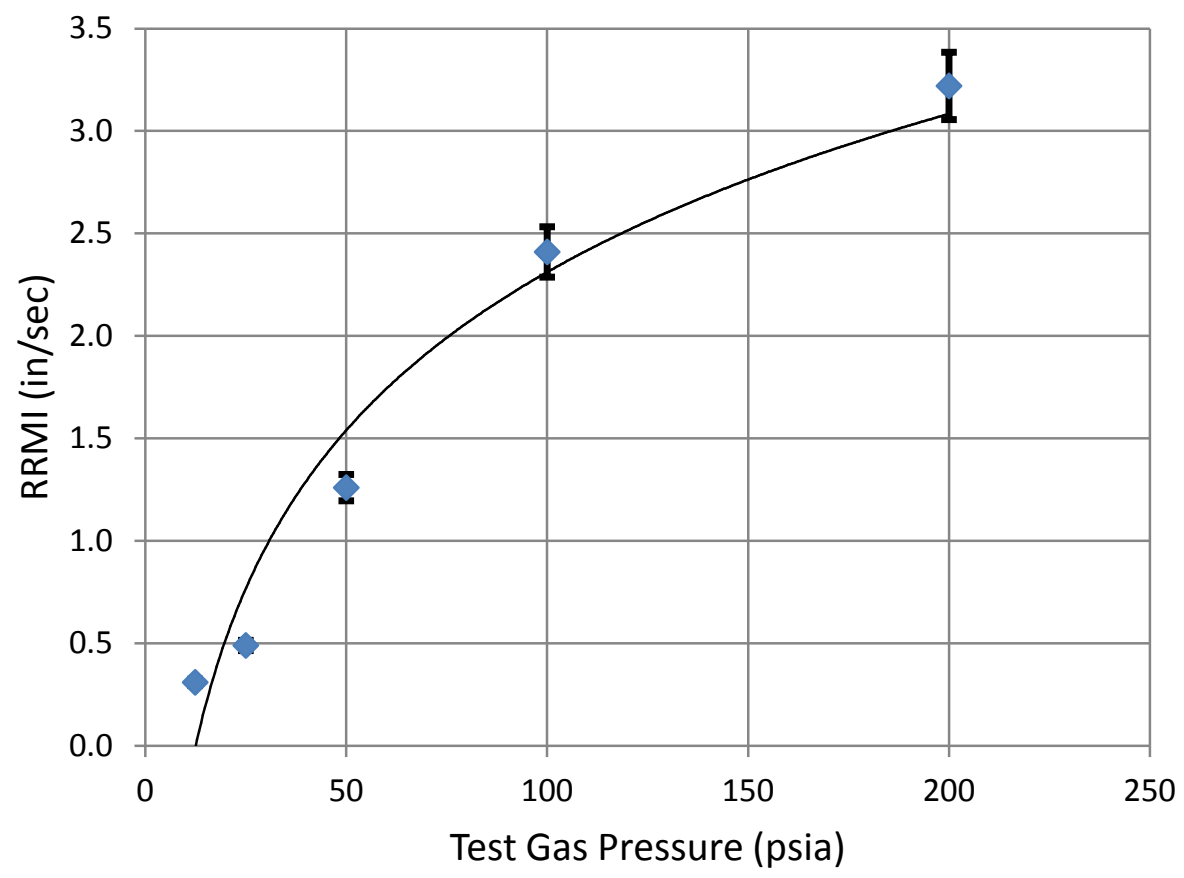

FIG. 10 -Plot of burning rate (RRMI) of $1 / 8$ in. (3.2 mm) diameter CP Ti rods in $100 \% \mathrm{O}_{2}$ as a function of test pressure. 


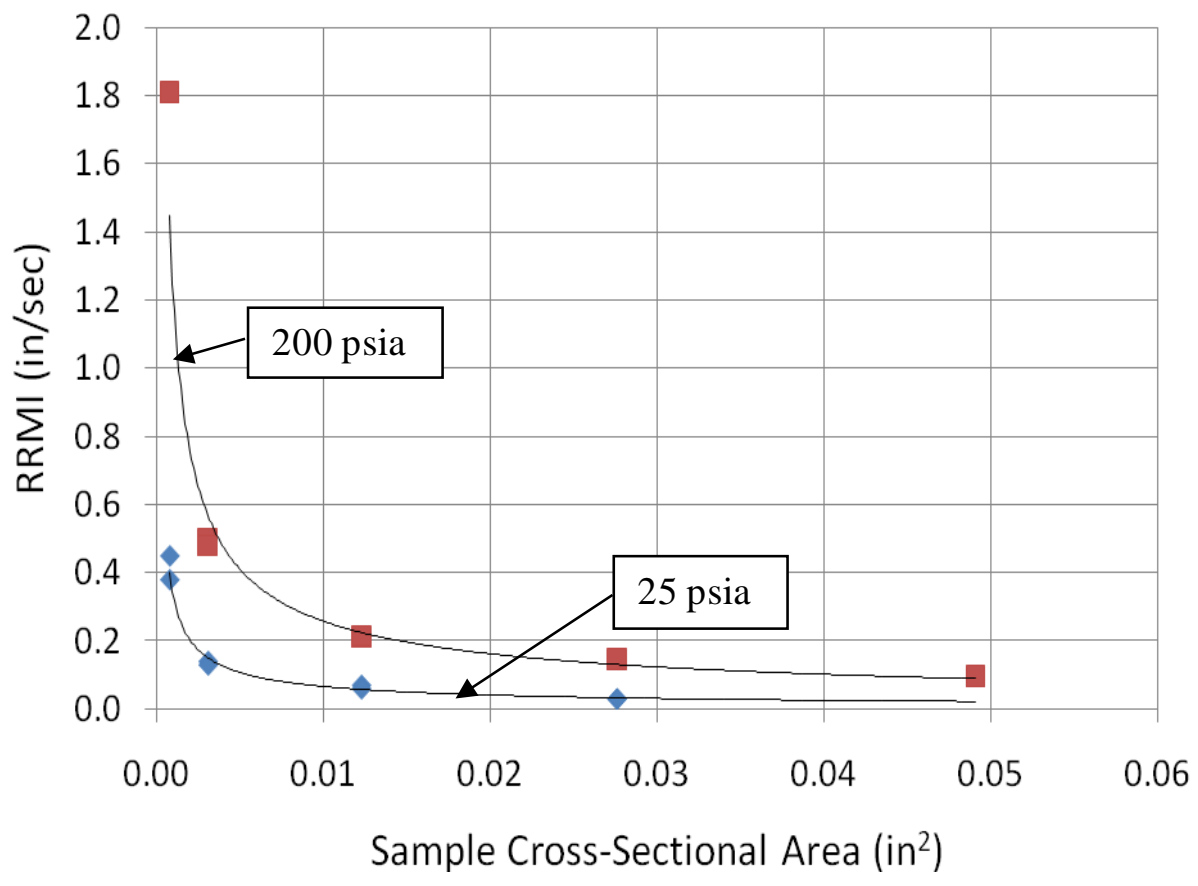

FIG.11-Comparison of the burning rates of CP titanium rods in $70 \% \mathrm{O}_{2}$ /balance $\mathrm{N}_{2}$ as a function of test gas pressure. (The uncertainty in each data point is smaller than the height of the symbol and is therefore not indicated on the plot.)

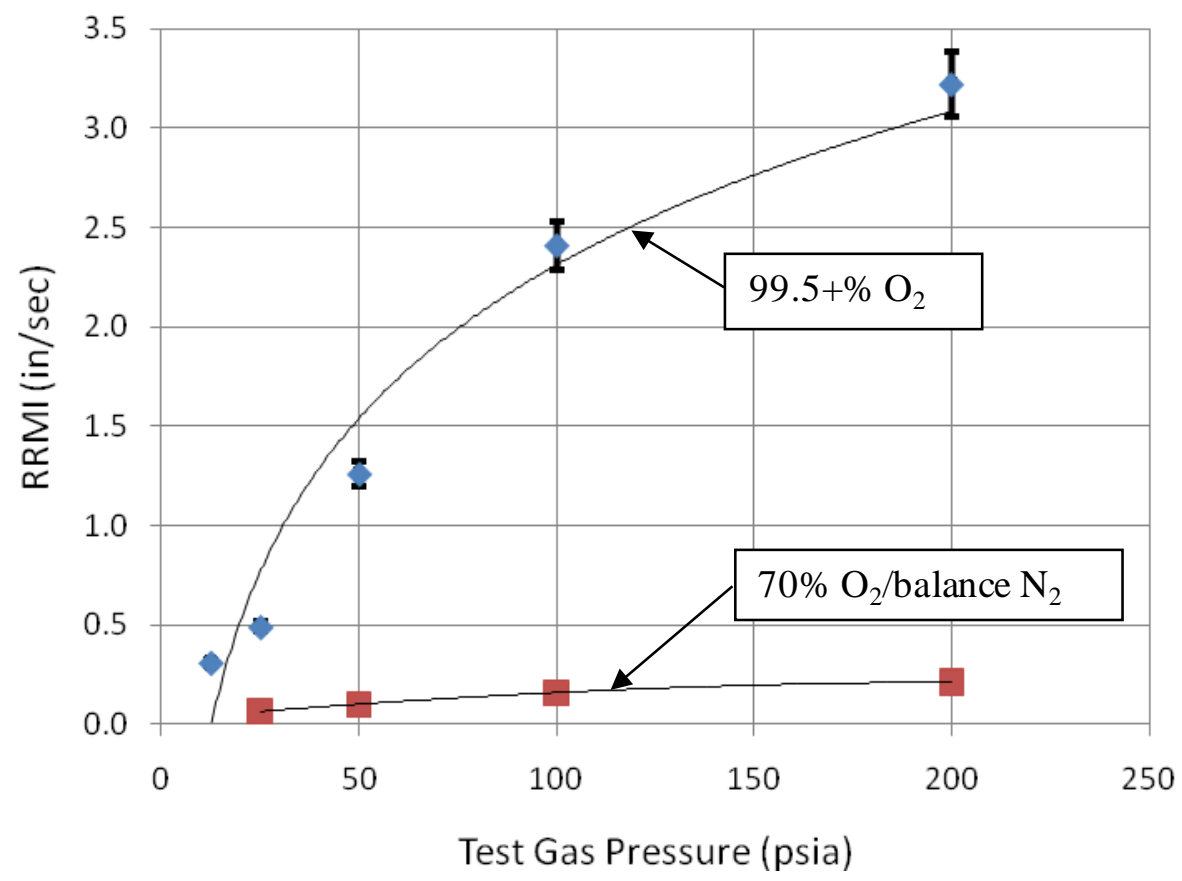

FIG. 12-Comparison of burning rates of 1/8 in. (3.2 mm) diameter CP titanium in pure oxygen versus mixed gas. (The uncertainty in each $70 \% \mathrm{O}_{2}$ /balance $\mathrm{N}_{2}$ data point is smaller than the height of the symbol and is therefore not indicated on the plot.) 